\title{
Hunting jellyfish
}

Why would anyone want to hunt jellyfish? Nasty, stinging animals, of no use to man or beast!

Such a response would not be unexpected from the majority of people. I was one of those, too, 30 years ago when I first started swimming out from the Mount Lavinia beach. We knew that at certain times of the year stinging jellyfish would appear. Anyone unfortunate enough to meet one of these would be in for an uncomfortable time. We usually swam out to near the reef S00 metres away, even during the south-west monsoon and had no way of returning quickly to the safety of the beach. I found that the safest ploy was to swim behind my two companions, making them into a human jellyfish shield.

Serious study of jellyfish and other marine animals able to sting commenced on the 13 October 1990. That was the day we first saw box jellyfish off Mount Lavinia and had a vague recollection that box jellyfish caused human fatalities. On the 7 October we had seen a lion's mane jellyfish estimated at $450 \mathrm{~cm}$ in diameter - again a never-to-be-forgotten sight when seen for the first time. It seemed a good idea to study and to identity marine animals that were of medical importance. Were they really dangerous? What precautions, if any, should we take and how should stings be managed? The results of the early studies were presented in my Presidential Address to the SLMA in 1992'.

Jellyfish are usually hunted, I read, using trawl nets towed behind boats. I also learnt that these animals were harvested for eating and that they were eaten also by a number of marine animals, such as turtles and sunfish, for instance. So they are not useless to man or beast. As we did not have access to trawl nets and boats but spent much of our free time in the sea, diving and beach combing, our study of jellyfish became restricted to those with which we had close encounters. Many jellyfish were found washed up on the beach, with seasonal variations. Encounters in the water also seemed to vary with the season. We were particularly interested in stinging jellyfish. After a time, we became familiar with these stingers through personal experience. At times when we came across an unknown animal someone volunteered to brush his arm against it. The final count of stinging jellyfish regularly encountered off the beaches of Colombo was four.

Jellyfish belong to the phylum Cnidaria, and like all members of that phylum, possess nematocysts borne on tentacles and sometimes on its umbrella (body). Nematocysts are little cells each armed with a harpoon-like filament able to inject venom into its prey or unsuspecting human. These discharge on contact, and being armed with barbs, are able to remain attached. If a portion of the tentacle breaks off, it can remain adherent to the skin held in place by the discharged nematocysts, and any undis- charged nematocysts may fire subsequently, eg. if the stung area is rubbed.

Vinegar was advocated at one time to inactivate undischarged nematocysts, but it is now not recommended except for box jellyfish stings. Carefully removing adherent pieces of tentacle, using forceps if possible, and gently washing the area is all that is required for stings in Sri Lanka. Relief of pain can be achieved by applying ice to the area. The pain of most stings resolves within two hours. The jellyfish off Colombo's beaches do not present a great hazard to swimmers and divers. They seldom appear in great numbers, and when they do, it is during the southwest monsoon when only the interpid few get into the water. Brief accounts on them follow.

\section{Physalia sp. (Portuguese man-o'-war, blue bottle)}

Physalia are easily recognised. They consist of a gas filled float with a cluster of short and long tentacles attached to the underside, all coloured blue. The whole organism (a colony of polypoid individuals) floats at the surface and is blown by the wind. The Sri Lankan forms have one long 'fishing tentacle' plentifully supplied with nematocysts. When the tentacle is contracted these nenr tocysts become crowded together into discrete 'button. and when extended, the nematocysts are more evenly spaced. As a consequence, stings resulting from a contracted tentacle produce a row of erythematous patches resembling a row of beads, but stings from an extended tentacle produces a linear mark.

Physalia are seen often in June washed up on the beach at Mount Lavinia when the seas are rough. Sporadic animals have been found till early November. However, they may be absent some years and numerous at other times, when one animal may be seen every 2 or 3 metres on the beach. They are difficult to spot in the water. The largest have been $6 \mathrm{~cm}$ in length, the commonest size being about $3 \mathrm{~cm}$. Sea bathers are occasionally stung.

The pain of the sting develops slowly to reach a maximum in 10 to 15 minutes. It fluctuates in intensity and begins to wane in 1 hour, resolving completely at the end of 2 hours. No erythema or weals have been observed in the stings we have sustained, but erythema in the form of linear streaks or beaded streaks are described. Our personal experience is that pain, though severe, is bearable. Stings covering larger parts of the body may be extremely painful and cause a lot of distress. In any event, all symptoms and signs resolve in 24 hours.

\section{Cyanea purpurea (Lion's mane jellyfish)}

Cyanea have been seen between July and October both in the water and washed up on the beach at Mount Lavinia. They are between 20 and $45 \mathrm{~cm}$ in diameter. In November of 1996 a large swarm of them were seen off 
Hikkaduwa when thousands of jellyfish swam north over a few days. Coloured lilac, with honey-brown spots over the upper surface and a dense cluster of filmly mouth parts, and hundreds of long tentacles underneath, they are unmistakeable.

Stings cause instantaneous pain with rapid development of erythema and weals. One sting on the forearm produced rows of erythematous papules $2 \mathrm{~mm}$ across spaced $6 \mathrm{~mm}$ apart. The pain subsides over 30 to $60 \mathrm{~min}$ utes, but may persist for a few hours if sensitive areas such as lips are stung. Erythema subsides over about 3 hours, the weals taking a few days to resolve completely, during which time they are mildly pruritic. As with stings of other Sri Lankan jellyfish no specific treatment is indicated. Pain caused by this jellyfish is usually mild rarely necessitating even the application of ice.

\section{Chiropsalmus buitendijki (Box jellyfish)}

First collected in 1990 off Mount Lavinia and incorrectly named (Chiropsalmus quadrumanus) in early articles, it was correctly indentified in September 1994. A related species (C. quadrigatus) is responsible for human fatalities off the Philippines. The feared sea wasp of Australia, capable of causing generalised symptoms or fatalities, is Chironex fleckeri, a larger animal with more tentacles.

The box jellyfish, as its name suggests, is box-shaped with sides $10 \mathrm{~cm}$ long. It is translucent and faintly milky. The pink tentacles arise in clusters at the end of four arms ('pedalia') placed at the four bottom corners. They are ribbon-shaped and $1 \mathrm{~mm}$ wide when extended, the nematocysts being arranged in transverse rows. The venom is very potent, and may cause localised cell damage that leads to superficial scarring that takes about 3 months to fade. Box jellyfish have been seen at Wellawatte and Mount Lavinia between June and October. Most have been damaged beach specimens with only a few seen in the water, usually just one or two at a time. However, in August of 1996 large numbers were encountered at Wellawatte, being carried north by the current off a popular public bathing beach, and we had a good opportunity to observe the effects of stings.

The pain of a sting developed slowly and was less severe than those caused by Physalia and Chrysaora. Erythematous weals appeared rapidly. Within $30 \mathrm{~min}$ the pain was replaced by pruritus and both weals and pruritus were waning at one hour. It took 36 to 48 hours for both to resolve. One person was stung on the back of the hand, leaving linear, pigmented marks that were still faintly visible three months later. Another was badly stung on his forearm, resulting in confluent weals that covered the greater part of the forearm and the back of the hand. He applied ice packs to these areas with some relief of pruritus. The box jellyfish seen in Sri Lanka does not cause problems. Its sting does not require specific treatment.

\section{Chrysaora quinquecirra (Sea nettle, Compass jellyfish)}

Chrysaora quinquecirra is undoubtedly the most beautiful and the most troublesome of Colombo's jellyfish. It is pink, and the umbrella is covered with cinnamon speckles crowded in groups to form 16 radially aligned bars over the umbrella, sometimes concentrated at the edges, colouring the marginal lappets (scalloped edge) deep red. Its four mouth-arms are long and pink, like frilly ribbons. White tentacles are arranged around the periphery. The diameter of the umbrella ranges from 3 to $10 \mathrm{~cm}$ and the mouth arms about $23 \mathrm{~cm}$ in the contracted state. They can be extended to about 2 metres in the larger animals. The tentacles can be greatly extended when hunting.

Chrysaora are seen throughout the year, in ones and twos in calm inter-monsoonal conditions and in swarms at the start of the south-west monsoon. Usually, in late April or early May, they are seen in large numbers at Wellawatte for a week or so, swimming north with the current. At this time they are very troublesome and sea bathers usually keep out of the water. The mouth arms themselves bear nematocysts. They often break off when the animals are swept over the reef and at times the water is full of mouth arm fragments, causing a mild but irritating stinging sensation over the whole body of sea bathers.

The sting of Chrysaora is very painful and felt instantaneously on contact. It is the most painful of the jellyfish stings, only exceeded by the hydroid Lytocarpus philippinus. An erythematous weal forms within $10 \mathrm{~min}$, reaching its maximum size after 30 , and fading thereafter. The pain subsides in about $30 \mathrm{~min}$. If many tentacles have made contact and pain is severe, ice may be applied. No specific treatment is indicated.

Although the stings of the jellyfish described above are generally mild with transient symptoms, it must be borne in mind that the effects of jellyfish venom is dose dependent. Extensive stings, particularly in children, the elderly and those debilitated or suffering from some other medical condition, may cause generalised symptoms that need appropriate care.

\section{Acknowledgements}

To my human jellyfish shields Nimal and Nileendra and all the other members of the Sri Lanka Sub Aqua Club who, through the years, braved the rough monsoon seas of Mount Lavinia and Wellawatte to hunt jellyfish with me, my grateful thanks.

\section{Reference}

1. Fernando M. Some hazards of diving. Ceylon Medical Journal 1992; 37: 72-80.

Malik Fernando, Physician and Naturalist, 12, Barnes Place, Colombo 7. 